\title{
New non-validated practice: \\ an enhanced definition of innovative practice for medicine
}

Ignacio Mastroleo [1-3]* and Felicitas Holzer [1-4]

1 National Scientific and Technical Research Council (CONICET), 1425 Buenos Aires, Argentina

2 Program of Bioethics FLACSO collaborating centre of PAHO/WHO, 1050 Buenos Aires, Argentina

3 Department of Philosophy, University of Buenos Aires, 1420 Buenos Aires, Argentina

4 Department of Philosophy, Sorbonne University, 75005 Paris, France

* Corresponding author: ignaciomastro@gamil.com

Key words: right to try, innovation in medicine, innovative care, innovative practice, distinction between research and practice

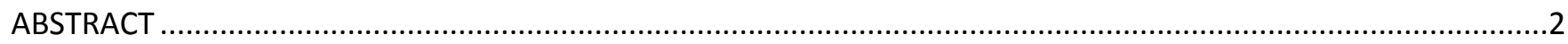

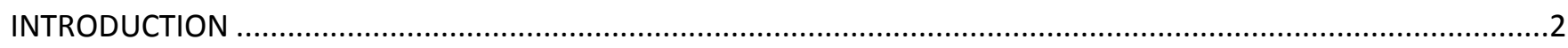

Table 1. Concise comparison of definitions of innovation in medicine and other fields................................4

Figure 1. Neutrality of the definition of innovative practice ...............................................................6

1. THE DEFINITION OF INNOVATION IN TRADITIONAL RESEARCH ETHICS ....................................................8

1.1. The Belmont Report's Definitions of Validated Practice, Research, and Innovation.................................8

1.2. Levine's Definition of Non-Validated Practice ......................................................................... 12

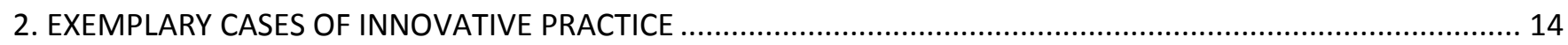

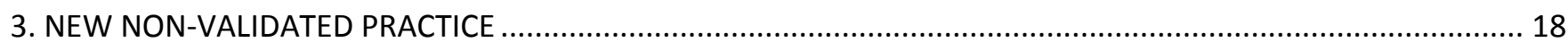

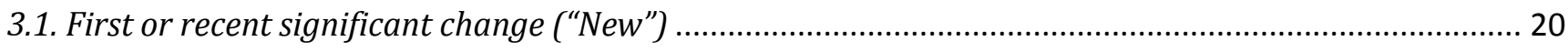

Table 2. 2D classification of medical practice characterized by validation and novelty ............................. 23

3.2. Insufficient evidence for regular healthcare ("Non-Validated") .........................................................26

Table 3. Evidence-based upper and lower conceptual bounds of innovative practice in medicine................ 28

3.3. Intention to Benefit Individual Patients ("Practice") ...................................................................... 33

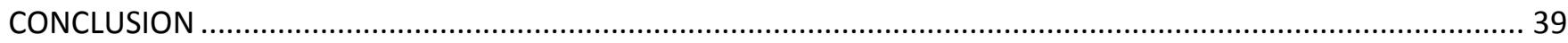

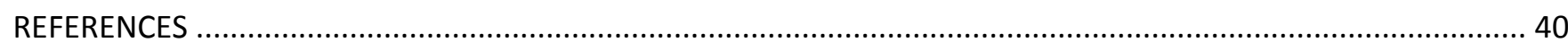

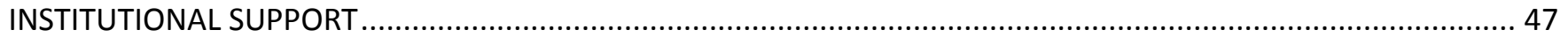

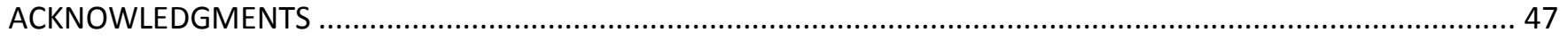




\section{ABSTRACT}

A significant part of the literature on innovative practice in medicine relates to seizing opportunities and curbing harms for patients in desperate situations. Unfortunately, the term innovation has multiple meanings and a rich rhetorical flourish that adds confusion and misunderstanding to an already difficult debate. This paper aims to enhance the current definition of innovative practice for medicine. First, we replace the term innovation with the more literal of new non-validated practice. To identify this meaning, we analyse the traditional research ethics' distinction between research, validated practice, and innovation in the Belmont Report. Second, we propose the following explicit definition of new non-validated practice: the first or recent use of diagnostic, therapeutic or preventive interventions that introduce a significant change, with an insufficient level of evidence of safety or efficacy for regular healthcare, and with the main aim to benefit individual patients. This definition is a promising conceptual tool to inform empirical research, ethicists, and the harmonization of its regulation and legislation (e.g. right-to-try laws).

\section{INTRODUCTION}

The activity of innovative practice and the concept of innovation have gained importance in medical ethics guidelines (Rietsma and Moreno 2006; Larcher et al 2018; ACOG 2015; ISSCR 2016), ethical literature (Taylor 2010; Sugarman 2012; Joffe 2014; Wilkinson \& Savulescu 2017; Schuklenk and Smalling 2017; London 2018; Holzer and Mastroleo 2019a, 2019b; Earl 2019) and current discussions of different "right-to-try" regulations in various countries (Cockburn and Fay 2019; Mastroianni 2006; Montgomery 2019; Miola 2015, 2019; Dresser 2016; Fins 2017; Savulescu 2017; Joffe and Fernandez Lynch 2018). The main background concern of this literature 
is seizing opportunity and curbing harm for patients in desperate situations and the dilemmas around it. However, the term innovation has multiple meanings and a rhetorical flourish that generates confusion and problems of communication to an already difficult debate (Baregheh, Rowley and Sambrook 2009). Hence, recent literature suggests to avoid the term innovation for study and regulation, or if it cannot be avoided, to be defined explicitly (Lilford 2018, Birchley et al 2019). Therefore, this paper aims to enhance the definition of innovative practice in two ways. Fist, we propose to curb the problem of rhetoric and multiple meanings of innovation by replacing it with the more literal of new non-validated practice and by distinguishing the specific meaning of innovation in medicine. To identify this specific meaning, we analyze the traditional research ethics distinction between research, validated practice, and innovation. Second, we propose the following unified definition of "new non-validated practice", that is, the first or recent use of diagnostic, therapeutic or preventive interventions that introduce a significant change ("new"); with an insufficient level of evidence of safety or efficacy for regular healthcare ("non-validated"); and with the main aim to benefit individual patients ("practice").

One easy way to show that the term innovation and its derivatives has a specific meaning in medicine, is to compare it to other widely used definitions of innovation in other fields (see Table 1).

\begin{tabular}{|l|l|l|l|}
\hline Term & Field & Author & Definition \\
\hline Innovation & Economy & $\begin{array}{l}\text { Shumpeter } \\
(1947)\end{array}$ & $\begin{array}{l}\text { Innovation is "the doing of new things or the } \\
\text { doing of things that are already being done in } \\
\text { a new way" (Schumpeter 1947, p. 151) }\end{array}$ \\
\hline $\begin{array}{l}\text { Technological } \\
\text { innovation }\end{array}$ & Technology & OECD (2002) & $\begin{array}{l}\text { "Technological innovations comprise new } \\
\text { products and processes and significant } \\
\text { technological changes of products and }\end{array}$ \\
\hline
\end{tabular}




\begin{tabular}{|c|c|c|c|}
\hline & & & $\begin{array}{l}\text { processes. An innovation has been } \\
\text { implemented if it has been introduced on the } \\
\text { market (product innovation)" (OECD 2002) }\end{array}$ \\
\hline $\begin{array}{l}\text { Innovative } \\
\text { therapy }\end{array}$ & Medicine & Taylor (2010) & $\begin{array}{l}\text { "Innovative therapy is the name we give to } \\
\text { novel medical interventions, radically } \\
\text { different from the standard of care, provided } \\
\text { in order to benefit a patient, rather than to } \\
\text { acquire new knowledge" (Taylor 2010, p. } \\
286 \text { ) }\end{array}$ \\
\hline $\begin{array}{l}\text { Innovation as } \\
\text { liminality }\end{array}$ & Medicine & Sethi (2019) & $\begin{array}{l}\text { "[Innovation is] a liminal approach that } \\
\text { stresses the importance of context and which } \\
\text { actively engages with - and at times embraces } \\
\text { - anti-structure, allows us to destabilise such } \\
\text { distinctions. It helps us acknowledge that } \\
\text { medical innovation is a space within which } \\
\text { both aims of individual benefit and } \\
\text { contributing to the wider stock of knowledge } \\
\text { can co-exist" (Sethi } 2019, \text { p.123) }\end{array}$ \\
\hline $\begin{array}{l}\text { Innovation as } \\
\text { new non- } \\
\text { validated } \\
\text { practice }\end{array}$ & Medicine & $\begin{array}{l}\text { Mastroleo and } \\
\text { Holzer }\end{array}$ & $\begin{array}{l}\text { "New non-validated practice is the first or } \\
\text { recent use of diagnostic, therapeutic or } \\
\text { preventive interventions that introduce a } \\
\text { significant change (section 3.1.), with an } \\
\text { insufficient level of evidence of safety or } \\
\text { efficacy for regular healthcare (section 3.2.) } \\
\text { and with the main aim to benefit individual } \\
\text { patients (section 3.3.)" }\end{array}$ \\
\hline
\end{tabular}

\section{Table 1. Concise comparison of definitions of innovation in medicine and other fields}

In economy, Schumpeter defines innovation broadly as "the doing of new things or the doing of things that are already being done in a new way" (Schumpeter 1947, p. 151). A more specific definition of technological innovation refers to new products and processes or significant changes 
and their introduction in the market ("product innovation") (OECD 2002). However, despite the family resemblance, the meaning of innovation in medicine we want to capture refers to an activity that has as its main aim the wellbeing of patients. For instance, Taylor states that "innovative therapy is the name we give to novel medical interventions, radically different from the standard of care, provided to benefit a patient, rather than to acquire new knowledge (Taylor 2010, p. 286). What will strike some readers is that the term innovation at stake refers to a special form of medical practice, rather than to a research activity (National Commission 1979, Taylor 2010, Sugarman 2012). Neither the economic nor the technological definition considers the main aim or intention of the innovative activity. Hence, they cannot capture this specific meaning of innovation in medicine. This is important because medical practice and medical research have different legal and ethical regulations that include different economic, administrative, and judicial consequences (Mastroianni 2006; Taylor 2010). Taylor's definition of innovative therapy does capture the main aim of innovative practice and distinguish it from the main aim of research ("acquire new knowledge"). It should be mentioned there are also tendencies to blur the researchpractice distinction regarding the term innovation as a medical activity. Lately, Sethi (2019, p. 123f) has defined as a "liminal approach" that, depending on the context, should be seen as a space that comprises both, features of research and practice.

While Taylor's term "innovative therapy" is too narrowly tailored to therapies (as innovative practice applies also to diagnostic and preventive measures, not only therapies), Sethi's account seems to refer to more general "terrains" or new innovative medical fields. As we will argue, a unified definition such as new non-validated practice avoids the ambiguous term "innovation" and captures both the main aim and appropriate scope of innovative practice as diagnostic, therapeutic, or preventive measure. Furthermore, if sound, our enhanced definition of new non- 
validated practice allows comparing activities in different fields of medicine that previously have been considered unconnected (e.g. compassionate use of investigational drugs, humanitarian uses of devices, novel off-label uses, etc.). In turn, since the definition of innovative practice is logically prior to its justification and regulation, it also provides a promising conceptual tool to inform empirical research, discuss responsible access to innovative care and evaluate the regulation of innovative practice (e.g. right-to-try laws).

However, before proceeding, we would like to make two clarifications. First, that new nonvalidated practice is a neutral definition of innovative practice. We understand that a definition is neutral if it can capture all relevant cases of innovation, whether successful or failed (outcome neutrality), responsible or irresponsible (moral neutrality) (see figure 1). Here, we agree with Lipworth et al. that neutrality regarding ethical justification and regulation is an essential feature of an adequate definition of innovative practice because we want to have room for reasonable disagreement and avoid using the definition as a rhetorical wand that can compromise critical evaluation (Lipworth et al. 2018, p.101).

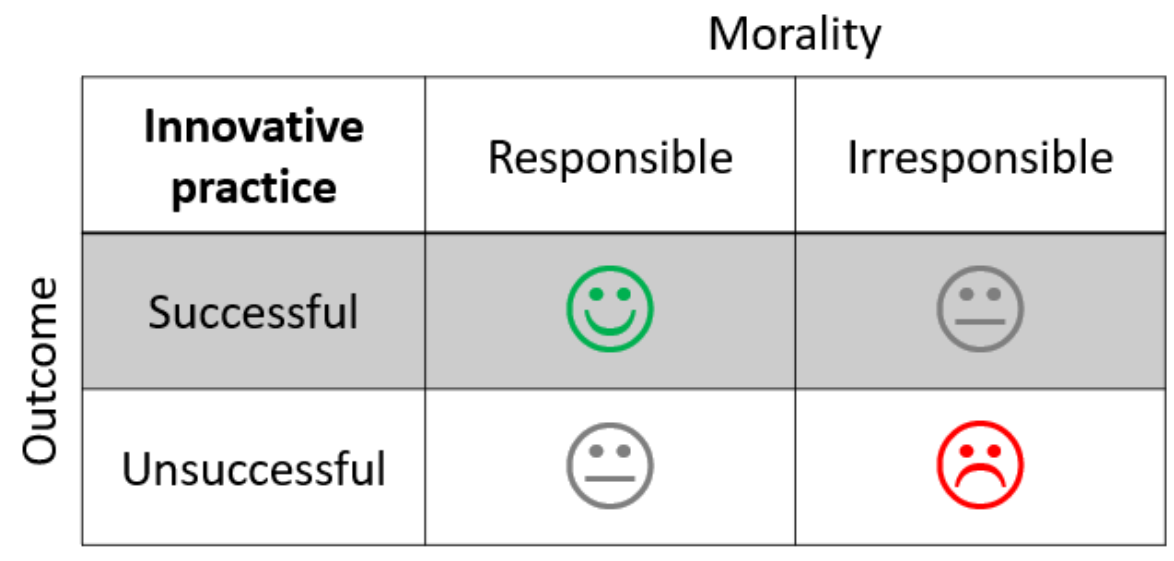

Figure 1. Neutrality of the definition of innovative practice 
Second, we want to clearly state that a systematic analysis of the ethical justification and regulation of innovative practice is outside the scope of this paper. The ethical problem of innovative practice can be broken down into three interrelated questions. First, what is innovation in medicine? (definition). Second, is innovation ethically permissible? (justification). Third, if permissible, what are the ethical principles and appropriate governance of innovation? (regulation). In view of our aim, in this paper we will mainly focus on the first question. However, we will sometimes need to present substantive positions to show how our definition works. When we do this, we will explicitly present these positions as maintained either by the defenders or detractors of innovation and rely on most commonly held ethical principles and frameworks of responsible innovative practice when needed (e.g. Taylor 2010, WMA 1964 [2013], para. 37, ACOG 2015, ISSCR 2016, Larcher et al 2018).

To defend our proposal, we will proceed as follows. In section 1, we analyze the definition of innovation in traditional research ethics. We revisit the distinction between research, validated practice, and innovation in the Belmont Report. Finally, we reconstruct Levine's definition of nonvalidated practice. ${ }^{1}$ In section 2 , we present a selection of exemplary cases to show why innovative practice is usually considered a valuable medical activity that is different from both validated practice and research. This preliminary conceptual analysis and the exemplary cases help us to develop the conceptual core of our proposal. Readers familiar with this discussion may want to skip ahead to section 3. In section 3, we introduce our definition of new non-validated practice and critically analyze its components. To avoid confusions with related activities, we also introduce a

\footnotetext{
${ }^{1}$ In our knowledge, this is first attempt in the literature to eliminate the term innovation from the definition of innovative practice, a path that we and other authors have followed (Birchley et al 2019).
} 
four-category classification of interventions used in medical practice that logically follows from our proposal

\section{THE DEFINITION OF INNOVATION IN TRADITIONAL RESEARCH ETHICS}

\subsection{The Belmont Report's Definitions of Validated Practice, Research, and Innovation}

According to Beauchamp and Saghai (2012), the National Commission for the Protection of Human Subjects of Biomedical and Behavioral Research (hereinafter the Commission) established two classes of activities labeled "research" and "practice" as categories for medical activities that are logically distinguishable from each other (although they may coexist in complex activities). The practical aim of this distinction in the Belmont Report is to establish what kinds of activities must undergo special regulations and ethical review by institutional review boards. However, the distinction is not drawn between research and practice as such, but between research and validated practice ${ }^{2}$. Hence, the Commission defines validated practice as follows:

[F]or the most part, the term [validated] "practice" refers to interventions where: (P1) the purpose of an intervention is "to provide diagnosis, preventive treatment, or therapy"; (P2) the intervention is "designed solely to enhance the well-being of an individual patient or client" (though benefit to other persons is sometimes the goal); (P3) the intervention has "a reasonable expectation of success" (National Commission 1979; as quoted in Beauchamp and Saghai, 2012, p. 52, edited).

2. Here, we interpret standard practice in the prescriptive sense that it has a sufficient level of evidence of safety and efficacy for regular healthcare use. As we will later discuss, we are aware that the term "accepted or standard practice" used in a descriptive sense may not always refer to validated practice (London 2006, p. 28-9). 
In our interpretation of the scope condition (P1), the term "practice" refers to preventive, diagnostic, or therapeutic uses of medical interventions, as well as-we will include as a logical addition - their combination. However, the necessary condition that defines practice is the design condition (P2); that is, if a medical intervention's main aim is to enhance the well-being of an individual patient. Hereinafter, we will drop the "solely" in the formulation of (P2). This does not present a particular problem for traditional research ethics, since the Belmont Report includes both a wide and narrow formulations of the practice condition. Practice, in a narrow sense, refers to paradigmatic cases of the doctor-patient relationship (Beauchamp and Saghai 2012, p. 54). However, the Belmont Report also formulates design condition (P2) in a broad sense as "an intervention designed to enhance the well-being of a particular individual or groups of individuals" (National Commission 1979, note 1). This broad formulation logically captures the narrow paradigmatic sense of practice, as well as non-paradigmatic cases of practice, for example, interventions designed only to enhance the well-being of others (e.g., blood donation and organ transplant) and interventions designed to enhance the well-being of an individual and others (e.g., vaccination) (Levine 1979, p. 22; National Commission 1979, note 1).

The remaining question is how to interpret the validation condition (P3) of "reasonable expectations of success". Reasonable expectations of success vary in different contexts. Here, we wish to distinguish between two different contexts, that is, the use of an intervention in regular healthcare and the use of an intervention for patients with unmet health needs and no reasonable alternatives. We will argue that, for validated practice, the validation condition (P3) should be interpreted as referring to the use of interventions in regular healthcare contexts. If this is the case, all exemplary cases of innovation fail, by definition, to meet the evidence threshold of sufficient validated practice at the time they were first used. 
The Commission also defines research as follows:

To qualify as research two conditions are central. The first is not a necessary condition for all forms of research, but the second is a necessary condition: (R1) there is (in pertinent research methods) a formal protocol-controlled design to test a hypothesis; (R2) there is an organized design 'to develop or contribute to generalizable [scientific] knowledge'. (National Commission 1979; as quoted in Beauchamp and Saghai 2012, p. 52).

The design condition (R2) of "generalizable [scientific] knowledge" defines research according to the traditional view. The Commission differentiates "generalizable knowledge" gain through research from other forms of knowledge gained through medical learning activities ${ }^{3}$. They recommend that if an activity has an organized design "to develop or contribute to generalizable knowledge," it should undergo a research review to protect human subjects, irrespective of the fact that the intervention is also intended to provide a direct health benefit for an individual patient (Levine 1979, p. 23). Thus, the Belmont report established a precautionary measure to prevent researchers from taking advantage of a loophole in the oversight system by presenting research with components of care under the label of "practice" to avoid the review process (Beauchamp and Saghai 2012, p. 43). However, this measure does not apply to uses of interventions with the main aim to the benefit of an individual patient with insufficient level of evidence of safety or efficacy for regular healthcare, if they do not have evident research components (e.g. .

\footnotetext{
3 “[...] knowledge gained through research must be oriented toward the types of generalizations found in scientific theories, scientific laws, and statements of relationships, in contrast to the learning that occurs in particular cases through astute clinical observations or diagnostic tests" (Beauchamp and Saghai 2012, p. 52)
} 
Finally, the Commission introduces a further distinction they call innovation and that cannot be regarded as validated practice or research:

When a clinician departs in a significant way from standard or accepted practice, the innovation does not, in and of itself, constitute research. The fact that a procedure is "experimental" in the sense of new, untested, or different does not automatically place it in the category of research. Radically new procedures of this description should, however, be made the object of formal research at an early stage in order to determine whether they are safe and effective. Thus, it is the responsibility of medical practice committees, for example, to insist that a major innovation be incorporated into a formal research project (National Commission 1979, emphasis added).

In the Belmont Report, innovation is defined mainly in terms of novel interventions that significantly depart from validated practice, but retain their main aim to benefit patients. The Commission refers less clearly to non-validation ("untested" procedures). Innovation does not constitute research even if it entails a relevant change in the benefit-harm profile of an intervention in comparison with standard practice. As we will discuss, this implies that the practice-research distinction in traditional research ethics is not related to the harm-benefit profile or soundness of evidence of a medical activity. Whether an activity is research or practice depends on what the activity is designed to do, that is, its main aim or intention (and the appropriate means used to pursue them). The Commission does neither consider innovation to be a grey zone between research and practice (King 2002), nor introduce a third sui generis category of activities for innovation (Lotz 2013). Instead, as we will argue following Levine, the Commission considers innovation as practice because its main aim is to benefit individual patients. 
As a result, commissioners and staff were concerned about underprotection of patients. Toulmin and others even hypothesized that certain medical practices, such as innovative therapies, were potentially more risky than well-design research (Beauchamp and Saghai 2012, p. 50; Fins 2017). Hence, the Commission went beyond defining innovation in the Belmont Report. They supported the view that the oversight of innovation should be improved and advised "medical practice committees" (not IRBs or research ethics committees) are responsible that innovation should be made the object of formal research at some point. But eventually the Commission fell short of proposing regulations for innovation. They made that decision because the National Research Act was about research and the politics of institutional forces in medicine would not allow any venture into the regulation of practice (Beauchamp and Saghai 2012, p. 4550; Fins 2017).

\subsection{Levine's Definition of Non-Validated Practice}

Levine (1979) offers a thorough analysis regarding the concept of innovation based on the Commission's different reports. According to Levine (1979), the purpose of the Commission in introducing the term innovation has been to avoid common confusion with research because they share the attribute of significant change from accepted or standard practice. However, Levine suggests abandoning the term innovation for a better term and defines this subclass of practice as follows:

Nonvalidated practices [sic.]. A class of procedures performed by physicians conforms to the definition of "practice" to the extent that these procedures are [P2] "designed solely to enhance the well-being of an individual patient or client." However, [not P3] they may not have been tested sufficiently often or sufficiently well to meet the standard of having "a 
reasonable expectation of success." The Commission uses various terms to describe these procedures: [e.g.] "innovative therapies" [...]. In my opinion, the best designation for this class of procedures is "nonvalidated practices" [sic.]. Novelty is not the attribute that defines this class of practices; rather, it is the lack of suitable validation of the safety or efficacy of the practice (Levine 1979, p. 22, edited).

First, although here the scope condition (P1) is not mentioned it is implied. In later work Levine clarifies that "the Commission's reasoning about how to deal with such practices applies to diagnostic and preventive measures, not only therapies" (Levine 2008, p. 218). Hence, "innovative therapy" (Taylor 2010) and its derivatives does not capture the full extension of the term innovation in research ethics or is confusing. This is the case because if taken literally, it restricts the scope to just one of the three possible uses of a medical intervention. Second, Levine disregards novelty as a defining attribute of innovation. In section 3.1, we argue this is a mistake and try to amend it. Third, for Levine, what makes practice non-validated is the failure to meet "reasonable expectations of success" condition (not P3). In section 3.2, we contend that both the Commission and Levine understand "reasonable expectations of success" as referring to the level of evidence an intervention should meet to be used as regular healthcare. Finally, Levine considers an intervention as practice if it meets the design condition of "enhancing the well-being of individuals" (P2). Although Levine quotes the narrow ("solely") formulation of design condition (P2), we will interpret it in the wider sense, as discussed above. Levine's conceptual analysis sheds light on the fact that the Commission considers innovation as a form of practice, not research or other sui generis category. In section 3.3, we will further inquire what it means for an intervention to be considered practice in the Commission's sense. But before developing our proposal in full, it 
will be useful to firstly flesh out to the concept of innovation to make it more comprehensible to the general reader.

\section{EXEMPLARY CASES OF INNOVATIVE PRACTICE}

Before developing our proposal, we outline three exemplary cases of what we consider innovation in medicine, already within the definition of traditional research ethics. Our aim here is to give the reader an intuitive grasp of the circumstances where innovation occurs. To save space, we have imposed two restrictions: first, we only provide exemplary cases of therapeutic and diagnostic uses, but not preventive interventions ${ }^{4}$; second, we skip classic examples of innovation in surgery in favor of cases with drugs, biologicals and devices where the discussion is less welldeveloped. 5

Our first exemplary case of innovation refers to the successful therapeutic use of an intervention:

The Farrows: stem cell transplantation of umbilical cord blood. In 1988, Matthew Farrow, a 5-year-old patient with Fanconi's anemia who had no reasonable medical alternatives for treatment, received the first successful umbilical cord blood transplant from his baby sister, Alison Farrow, based on sound scientific evidence, including animal studies (Gluckman et al. 1989; BBC 2001). Since this first successful transplantation, cord blood is now widely used as a treatment with hematopoietic stem cells for a wide range of

\footnotetext{
${ }^{4}$ For instance, preventive uses of interventions for Ebola Virus Disease under the Monitored Emergency Use of Unregistered Interventions (MEURI) framework could be regarded as an exemplary case of preventive new non-validated practice (WHO 2018).

${ }^{5}$ Here we follow the authors that consider innovative practice can be applied to both technologies and surgery in medicine (Taylor 2010, table 1)
} 
malignant and non-malignant conditions (Gluckman et al. 1997; Taylor 2010; Sugarman 2012).

Intuitively, we argue that successful cases such as Matthew Farrow illustrate the potential benefits of innovative practice, which serves as a basis for defending it for patients with unmet health needs, serious conditions and no reasonable, validated medical alternatives in frameworks of responsible innovation.

Nevertheless, the use of new non-validated interventions that aim to benefit individual patients does not always attain the desirable results for patients deprived of alternative validated options. Therefore, consider the following case of a failed therapeutic use of an intervention:

Jim Gass: stem cell therapies. The case of Jim Gass caused an outcry in international media that illustrated a growing concern about the number of "stem cell tourists" worldwide. He had several stem cell interventions at private clinics in Mexico, China, and Argentina, paying tens of thousands of dollars each time for injections to recover from a stroke. The total cost, including travel expenses, reached 300,000 US dollars. Eventually, Jim Gass developed a tumor in his lower spinal column. The subsequent tests showed that the tumor mass was made up of abnormal, primitive cells that were growing aggressively (Kolata 2016).

Someone may claim that the case of Jim Gass is not an exemplary case of responsible innovation but one of potentially inappropriate or futile use of cell therapy. This is a reasonable claim, and it will be discussed in section 3.2. However, this case is useful to remind us that our proposal is neutral and captures all cases of innovation, whether successful or unsuccessful, responsible or irresponsible. 
As implied in the scope condition (P1), examples of using new and unproven interventions outside of sound research are not limited to therapeutic and preventive procedures and can also be exemplified by diagnostic use of interventions.

Genome sequencing for rare diseases. Two siblings in the United Kingdom with an unusual muscle wasting disease had to wait 20 years until they were diagnosed at a cost of more than 14,000 pounds sterling. Whole exome sequencing, costing approximately 1,000 pounds at this time, revealed that a heterozygous mutation was likely disease causing (Perdeaux 2013; Rehm et al. 2015).

Although genomic sequencing does not "intervene" in the sense it can change the patient's genome like gene editing, new diagnostic tools are interventions in the sense that they have the potential to change a given patient's life prospect. Patients who suffer from rare diseases are usually in this situation. They often face unsuccessful and burdensome diagnostic procedures over several decades. Despite the uncertainties of our genetic knowledge, rapidly diagnosing a rare disease could be crucial to avoid distress, and unnecessary potentially harmful therapeutic interventions. Moreover, in some cases molecular diagnosis of rare diseases may lead to improved treatment or preventive decisions. In the defenders' view of responsible innovation, considerations of this kind make the benefit-harm profile of new non-validated diagnostic interventions positive for the use in a limited number of patients, despite its inherent risks. Therefore, some uses of genome sequencing technologies, including whole genome and whole exome sequencing for patients with rare diseases, are recent exemplary cases of innovative practice, precisely when they are not sufficiently validated for regular healthcare. 
Finally, innovative practice can be the result of combining different interventions with different purposes for the main aim to benefit an individual patient:

The Nashes case: IVF, cord blood transplant, and PGD. Molly Nash was born in 1994 with type-C Fanconi's anemia, a more aggressive type than that affecting Matthew Farrow. Lacking a suitable match for a bone marrow transplant, the Nashes conceived a baby they named Adam to be a suitable umbilical cord blood donor that possibly matched with Molly. However, due to their low probability of having a baby without Fanconi's anemia, the parents had to use three different interventions - namely, in vitro fertilization (IVF), preimplantation genetic diagnosis (PGD), and umbilical cord blood transplantation-to have an acceptable donor. The PGD was used twice, first to select an embryo without Fanconi's anemia and then to find a match for Molly (Faison 2005).

As Kahn and Mastroianni (2004) note, the chosen interventions in the Nashes' case had sufficient level of evidence of safety and efficacy to be used in regular healthcare for their intended indications in 2000 when Adam was born, so they were separately considered validated practices. However, the combination of these interventions -necessary to attain a more promising treatment for Molly6 - was still considered an innovation ("experimental procedure") at that time and was not covered by insurers (Kahn and Mastroianni 2004, p. 92).

As Taylor notes, exemplary cases of innovative practice do not follow the linear model of basic research, to translation, to clinical research, and eventually to its application. Instead, innovative practice comes from thinking backward from a patient's perspective and forward from deep

\footnotetext{
${ }^{6}$ As Faison states "A bone marrow transplant, in which diseased cells are killed off and replaced with new donor cells, is the only cure for progressive bone marrow failure. But the procedure is risky at best. When Molly Nash was born, the success rate of a transplant from an unrelated donor was a dismal 18 percent. However, under the right circumstances, the success rate for transplants from a brother or sister was as high as 65 percent" (Faison 2005).
} 
knowledge of how the body functions and interacts with the disease to challenge the limits of current therapeutic, preventive, and diagnostic interventions (Taylor 2010, p. 286). For those who believe innovative practice is ethically justified, novel and as yet untested interventions can be an option for patients who lack reasonable medical alternatives for their health conditions despite the uncertainty of such interventions in terms of risks and potential benefits.

Having introduced some exemplary cases of innovation, we now introduce our proposal of a refined definition of innovation for research ethics.

\section{NEW NON-VALIDATED PRACTICE}

We propose to define innovative practice as new non-validated practice, that is, the first or recent use of diagnostic, therapeutic or preventive interventions that introduce a significant change, with an insufficient level of evidence of safety or efficacy for regular healthcare and with the main aim to benefit individual patients. Levine's definition of non-validated practice focuses only on non-validation (insufficient evidence of safety or efficacy) and leaves out the characteristic of novelty. We suggest that it is the conjunction of both novelty and non-validation that defines innovation in traditional research ethics. However, we agree with Levine and the Commission that innovation is a subclass of practice and not of research. Hence, we see our definition as a continuation and refinement of what we call the traditional research ethics view.

But before proceeding, we would like to explain the rationale for grounding our proposal on this view. Essentially, we think the traditional research ethics analysis of innovation harmonizes with most of the current discussion on the literature of justification and regulation of innovation and yields a greater practical impact than other alternatives such as innovation as "a grey zone" between research and practice or as a sui generis activity (e.g. King 2002, Lotz 2013). First, the 
defenders of innovation consider responsible innovation in certain circumstances not only ethically permissible medical practice for patients, but sometimes also an obligation on the part of doctors (London 2006)7 ${ }^{7}$ However, this does not mean uncritically defending the current way of regulating innovative care. For instance, Taylor (2010) proposes to improve the current regulatory landscape with an independent oversight mechanism, which does not mistake innovative practice for research. Also, Sugarman argues that doctors have an obligation to incorporate innovation into sound research in a timely manner after experience with, at most, a few patients (Sugarman 2012, ISSCR 2016). These authors also defend the position that innovation cannot be reduced to research, due to its complex nature (Agich 2001, Taylor 2010). Second, authors who meaningfully disagree with innovation's defenders also use the same meaning of innovative practice. These detractors argue that innovative practice should be prohibited on ethical grounds, and usually propose standard research protections as appropriate regulation for all non-validated interventions (Agich 2001). For instance, they claim that "last chance" unproven interventions should only be accessible through research studies designed to evaluate the safety or efficacy of new interventions (Emanuel 2013). ${ }^{8}$ Third, the concept of innovation is used even under learning healthcare systems, in which the sharp distinction between research and practice of the current system is allegedly "blurred" (Kass et al. 2013). For instance, Faden et al. (2013) explicitly use a similar definition of innovation or non-validated

\footnotetext{
${ }^{7}$ London identifies this as a special category within a wider spectre of innovation and names it "innovation as emergent problem-solving" (London 2006, pp. 45-46).

8 "6. Research of Unproven, "Last Ditch" Treatments: In the treatment of a patient, where proven interventions do not exist or have been ineffective, the physician, after seeking expert advice, with informed consent from the patient or a legally authorized representative, may use an unproven intervention to promote the patient's health or well-being, but only if it is undertaken as a research study designed to evaluate its safety and efficacy. Repeated uses of an unproven intervention can only be justified as part of a research study that fulfils all the protections in this Declaration" (Emanuel 2013, emphasis added).
} 
practice, as do the Commission and Levine. ${ }^{9}$ Similar to Taylor (2010), they propose regulatory measures, such as oversight and systematic assessment of innovative practice and other practice that has not been rigorously evaluated. Moreover, they explicitly state that they will not simply expand the current review system for research to solve the problem of patients' underprotection from insufficient validated practice (Faden et al. 2013, p. s24). This brief summary of the literature shows that despite the differences on matters of justification and regulation, all the authors referred to above share the Commission's and Levine's concept of innovation.

Hence, to introduce our proposal of new non-validated practice, we now analyze its three core elements.

\subsection{First or recent significant change ("New")}

In Levine's analysis, the defining attribute of innovation is "[...] the lack of suitable validation of the safety or efficacy of the practice" (Levine 1979, p. 22). However, we suggest that it is the conjunction of both novelty and non-validation that captures the specific meaning of the term innovation in traditional research ethics. Hence we first need to delineate the concept of novelty.

We stipulate that in the attribute we call "novelty," the term "new" refers to the recent or first use of an intervention that introduces a significant change in the context of medical practice. Here, it is useful to differentiate "significant change" from "mere variation" or non-significant change

\footnotetext{
9 "Health care institutions and clinicians are constantly adopting new practices, ranging from platforms to support clinical decision-making built on electronic health systems to minimally invasive and robotic surgery. These innovations are often introduced without systematic assessment of their impact, perhaps to avoid crossing the unwelcome and curious divide between practice and research. Our framework makes this distinction irrelevant to questions of oversight and provides reasons why health care institutions and professionals are obligated to accompany the introduction of such innovations-as well as practices that have never been rigorously evaluated - with a commitment to systematically learn about their effects on clinical outcomes, health care value, patients' experience, and heath disparities" (Faden et al. 2013, p. s24-5)
} 
(London 2006, p. 31; ACOG 2015, p. 5) to avoid including meaningless changes in practice under the label of innovation. For example, medical powdered gloves have been extendedly used since the 1990s due of concerns with HIV (Palosuo et al. 2011). Replacing blue with indigo gloves would probably not be considered a significant change in most cases. However, a change from powdered latex globes to nitrile or non-powdered latex gloves could be a significant change, and hence an innovation, given that latex allergies are a major concern (Palosuo et al. 2011). More formally, one criterion proposed to distinguish between innovation and mere variation is that a change is significant if it entails a relevant modification in the benefit-harm profile of the use of an intervention, given a specified context (London 2006, p. 31).

Furthermore, we use the term "long-standing" as the logical opposite to "new" in the sense that it does not refer to the recent or first use of an intervention that introduces a significant change. In our analysis, we mainly use "new" and "long-standing" as terms that refer to continuous time properties of objects (segments of time), not discrete time properties (points of time). We define novelty as the "first or recent uses of an intervention" because something is new even if it has been used a few times. We cannot offer a precise limit to the use of the term "new" and say how many uses it implies for something to become "long-standing". However, we believe this is a positive feature of our definition because it does not settle matters corresponding to justification and regulation a priori. Also, in our definition of new non-validated practice, we take as the ideal meaning of novelty uses of interventions that have not been used before anywhere at any time. In principle, this implies that "new" or "long-standing" are not a country, hospital, or departmentspecific concept. For instance, if a long-standing validated intervention is used for the first time in Argentina (even though it has been used for 30 years in the US), it may not constitute an innovation according to our definition of new non-validated practice. It could be rather an 
implementation of a long-standing validated intervention. Time, country or other specific uses of the concept of novelty might be useful for practical purposes, such as for regulation or evidence extrapolation from one specific context to another. However, they do not replace the ideal meaning of novelty.

Consequently, once we introduce novelty and non-validation as two necessary attributes of the definition of innovation, we obtain a classification of four different categories of "practice"-still in the traditional research ethics sense-that is, the use of an intervention with the main aim to enhance patients' well-being (see Table 2). Within this classification, innovation refers to "new insufficiently validated interventions." The rest of the exemplary cases quoted in the table illustrate the remaining categories as we understand them. 


\begin{tabular}{|l|l|l|}
\hline Validation & \multicolumn{1}{|c|}{ New practice } & \multicolumn{1}{|c|}{ Long-standing practice } \\
\hline Non-validated practice & $\begin{array}{l}\text { New insufficiently validated } \\
\text { interventions (innovative } \\
\text { practice). } \\
\text { Examples: The Farrows, } \\
\text { Jim Gass, genomic } \\
\text { sequencing for rare } \\
\text { validated interventions. } \\
\text { diseases, and the Nashes } \\
\text { (section 2). }\end{array}$ & $\begin{array}{l}\text { Example: routine } \\
\text { episiotomy for vaginal } \\
\text { birth in 2009 (Carroli and } \\
\text { Mignini 2009) }\end{array}$ \\
\hline $\begin{array}{l}\text { Validated practice } \\
\text { New sufficiently validated } \\
\text { interventions. } \\
\text { Example: imatinib for } \\
\text { chronic myeloid leuchemia } \\
\text { in early 2000s (Druker } \\
\text { 2009) }\end{array}$ & $\begin{array}{l}\text { Long-standing sufficiently } \\
\text { validated interventions. } \\
\text { Example: amoxicillin for } \\
\text { 2018 (Sutherland et al. } \\
\text { 1972) }\end{array}$ \\
\hline
\end{tabular}

Table 2. 2D classification of medical practice characterized by validation and novelty

Our first argument for an enhanced definition of innovative practice is that conflating novelty and validation is a semantic confusion that can lead to false implications. An example of conflating 
novelty and validation is the following statement by King (2002, p. 574): “[...] how does innovation differ from standard medical practice? By virtue of its novelty it lacks reasonable expectation of success". Admittedly, both concepts correlate in many interventions, just like the concepts of "swan" and "white" do in many cases of birds, but not in all. Hence, if we conflate the novelty of an intervention with its having insufficient evidence, we incorrectly imply that either all new interventions used in practice are non-validated or all long-standing interventions are validated.

Second, even if novelty and non-validation are appropriately distinguished, defining innovative practice only in terms of "non-validation" is still confusing. If Levine's "non-validated practice" proposal is taken as equivalent to the definition of innovation in the Commission's sense, then cases of long-standing non-validated interventions, such as routine episiotomy-an incision of the perineum to facilitate the baby's birth-would fall under the category of innovation. However, no one would call routine episiotomy an innovation today, although it was introduced as such in the first half of the 20th century (Carroli and Mignini 2009). Christine Grady puts forward a similar objection to long-standing “off-label” uses of drugs (Sugarman 2017).

Third, we argue that our definition, and the classification for interventions used in practice that it implies (Table 2), help to avoid confusion and misunderstandings. On the one hand, it is crucial to distinguish new non-validated practice (innovative practice) from long-standing non-validated practice. Typically, the real-world problems of innovative practice are related to whether they should be used in or not at all (Larcher et al 2018), and if this is the case, when and how they should be made object of sound clinical research. However, cases of long-standing non-validated practice, like the current use of routine episiotomy or long-standing "off-label" uses, are different. The real-world problem is rather how to gather sufficient scientific evidence to establish a sufficiently valiedated harm-benefit profile of the intervention. Moreover, in the case of routine 
episiotomy, the relevant question is how to stop doctors from using accepted long-standing interventions when there is sound evidence that a practice lacks net clinical benefits (Carroli and Mignini 2009). These concerns can be extrapolated from routine episiotomy to other longstanding non-validated interventions, such as the off-label use of drugs or devices in reproductive and maternal health (Little and Wickremsinhe 2017). If this extrapolation is sound, it makes a distinction between new and long-standing non-validated practices even more useful.

On the other hand, it is also useful to distinguish between new and long-standing validated interventions to better understand the specific meaning of innovative practice for medicine. For instance, the drug imatinib for chronic myeloid leukemia is an exemplary case of new validated practice in the early 2000s after rational drug design and sufficient validation from expedited multiphase randomized controlled trials (Druker 2009, Chary 2016). Unlike the exemplary cases of innovation, imatinib did follow the linear model of basic research to clinical research and eventually to practice (Taylor 2010, p. 286). Therefore, it makes sense to talk about new validated interventions and distinguish them from exemplary cases of innovative practice such as the Farrows, Jim Gass, genomic sequencing for rare diseases, and the Nashes. In turn, we also argue that even though imatinib has been validated and has thus shown sufficient evidence for its regular use in healthcare for chronic myeloid leukemia in the early 2000s, its harm-benefit profile had not yet been fully established at that time. For instance, some rare adverse events are only known after long-standing use because they occur after thousands (or tens of thousands) of uses. Hence, long-standing validated interventions, such as amoxicillin for infectious diseases, usually have the advantage of a better-known harm-benefit profile than new validated practice.

Finally, with our classification we do not lose, but rather integrate and clarify, the insights of previous definitions of innovative practice. We resuscitate the Commission's intuition according to 
which it is important to highlight the attribute of novelty as the recent or first use of an intervention that introduces a significant change, since this is why new non-validated practice gets commonly confused with research. But we keep Levine's intuition that non-validation is a central attribute to distinguish in practice whether it is new or long-standing.

\subsection{Insufficient evidence for regular healthcare ("Non-Validated")}

Although "validation" is an epistemic concept, "insufficient validation for" is an ethical concept. Sufficient validation presupposes that an intervention has a sound level of scientific evidence of safety or efficacy for a certain use in certain contexts. Insufficient validation lacks this level of evidence. The proper task of ethics does not consist in establishing what this level of evidence is, but rather in justifying what reasonable agents can or are required to do given different levels of evidence, uses, and circumstances. Lastly, the preposition "for" is a reminder of the contextual nature of validation, that is, an intervention can be sufficiently validated for certain uses and contexts, but not for others.

In our present analysis, we take as a working hypothesis the defender's position that restricts the term innovation to interventions that are insufficiently validated for regular healthcare, but sufficiently validated as "last chance" interventions. Therefore, it is necessary to distinguish between regular healthcare and "last chance" contexts. Most notably, literature on regulation of innovation (Sugarman 2012, ISSCR 2016, Earl 2019) characterizes innovation as interventions with "reasonable chances of success." Here, they refer to a reasonable level of scientific evidence for the use of innovative care for individual patients with few or no acceptable medical alternatives. Note that, as Table 3 shows, both standards of reasonable expectations of success for regular healthcare and "last chance" interventions set the conceptual upper and lower bounds of 
innovation. Conceptually, as soon as the upper bound is surpassed, an intervention is validated practice. In turn, when the lower bound is surpassed, an intervention is futile. To keep our definition of innovation as neutral as possible, we will distinguish futility in a narrow sense from potentially inappropriate practice as we explain below.

\begin{tabular}{|c|c|c|}
\hline Type of practice & Level of evidence & Exemplary cases \\
\hline \multirow{2}{*}{ Validated practice } & $\begin{array}{c}\text { Sufficient level of evidence } \\
\text { of safety and efficacy for } \\
\text { regular healthcare. }\end{array}$ & imatinib for CML from early \\
& 2000s to date (Druker 2009). \\
\hline
\end{tabular}

\begin{tabular}{|c|c|c|}
\hline \multicolumn{3}{|c|}{ Upper bound: reasonable expectation of success for regular healthcare } \\
\hline $\begin{array}{c}\text { Innovation } \\
\text { (National Commission } \\
\text { 1979), } \\
\text { Non-validated practice } \\
\text { (Levine 1979), } \\
\text { Newnon-validated practice } \\
\text { (Mastroleo and Holzer), } \\
\text { Innovative practice, } \\
\text { (Earl 2019) }\end{array}$ & $\begin{array}{l}\text { - Insufficient level of evidence } \\
\text { of safety and efficacy for } \\
\text { regular healthcare. } \\
\text { - Sufficient level of evidence } \\
\text { of safety and efficacy for } \\
\text { "last chance" interventions. }\end{array}$ & $\begin{array}{l}\text { - Successful: The Farrows, the } \\
\text { Nashes (section 2). } \\
\text { Non-Successful: Jim Gass } \\
\text { (section 2), bone marrow } \\
\text { transplants for breast cancer } \\
\text { (ACOG 2015, p. 3). }\end{array}$ \\
\hline \multicolumn{3}{|c|}{ Lower bound: reasonable expectation of success for "last chance" interventions } \\
\hline Futile practice & $\begin{array}{l}\text { Sufficient level of evidence } \\
\text { of no safety or efficacy for its } \\
\text { use. }\end{array}$ & $\begin{array}{l}\text { - Antifungals for myocardial } \\
\text { infarction; CPR on a dead patient } \\
\text { (Bosslet et al. 2015, p. 1325) }\end{array}$ \\
\hline
\end{tabular}


Table 3. Evidence-based upper and lower conceptual bounds of innovative practice in medicine

Table 3 only provides a rudimentary outline of possible conceptual upper and lower bounds of evidence levels for innovation in cases of "last chance" interventions. This table represents the semantic fact that innovation is a relational or comparative concept (London 2006, p. 26), that is, a concept that needs a fixed point or baseline to be meaningful. In this case, the baseline of the concept "innovation" is the relevant level of evidence of safety or efficacy of certain use of an intervention in a certain real-world context (validation). In what follows, we want to explore this characteristic in more depth. We will discuss three substantive basic questions regarding 'validation'. To do this, we will present the defenders' position that at least certain cases of new non-validated practice are ethically permissible. Nevertheless, our aim is not to give an original justification, but to show that our definition harmonizes with this dominant view in the literature on innovation.

Our first question is about the appropriate level of evidence for regular healthcare use of interventions. Here, we want to explore the upper bound of innovation, that is, "reasonable expectation of success" for regular healthcare. Interventions accepted in medical practice may fall short of an appropriate scientific validation (Beauchamp and Saghai 2012, p. 49-50). That is, although they are regularly used, their harm-benefit profile remains underdetermined as to whether it provides net clinical benefit or not. However, this informed judgment can vary depending on what we consider adequate scientific methods of validation. Beauchamp and Saghai (2012) conclude that the commissioners of the Belmont Report never specifically addressed under which conditions a medical intervention or a hypothesis is validated. The Commission knew that there is no universal gold standard of validation. Multi-phase randomized controlled trials seek to 
systematically identify risks and adverse effects and assure that treatments that are to be approved are shown to be safe and effective (Rosemann, Bortz, and Vasen 2019). However, the scientific community usually accepts that sufficient validation of an intervention is not obtained only through the multi-phase trials system (Diaz and Neuhauser 2005). In fact, from a point of view of evidence-based medicine, "RCTs have never monopolized medical knowledge production" (Bothwell et al. 2016). Hence, there seem to be good reasons not to consider randomized controlled trials as a universal gold standard, but rather to adopt a case-by-case approach applying different research methods and methodologies to appropriate circumstances (Cartwright 2007). This latter position does not deny that in many cases, multi-phase randomized controlled trials are the appropriate standard of scientific validation. However, even if reasonable agents disagree about the appropriate level of evidence for validated practice or the methods of validation for the context of regular healthcare, they must agree if they rationally accept our definition, that innovative practice refers to the category of interventions that fail to reach that level (London 2006).

Our second question concerns the appropriate level of evidence for "last chance" uses of interventions in medical practice. In the literature, the term "last chance" refers to interventions for patients with serious conditions and unmet health needs. But "last chance" is not a synonym of a particular regulatory pathway of accessing innovative practice. Here, we want to examine the lower bound of evidence of innovation identified by the principle of "reasonable expectation of success". Translated into more contemporary research ethics language, this refers to an appropriate evidence level regarding the harm-benefit profile of an intervention for individuals who lack other reasonable alternatives. From the point of view of justification and regulation, this is a substantive issue. As stated by Sugarman (2012), the lack of reasonable medical alternatives 
for an individual goes along with a changed evaluation of the harm-benefit profile of an insufficient validated intervention compared to its use in regular healthcare. For the defenders, the fact that an individual has no alternative intervention can make a "last chance" intervention $e x$ ante a reasonable choice provided certain conditions are met, among them scientific validity. As in the case of validated practice for regular healthcare, the question about the sound level of evidence for "last chance" interventions remains open. Authors engaged in the "the right to try" debate, argue that for terminally ill patients, it should be the successful preliminary prospect of an intervention or, e.g., the successful approval of a phase I trial, or in some exceptional cases, just a reasonable scientific rationale and some relevant evidence (Dresser 2016, Savulescu 2017). According to the ISSCR guidelines, the assessment of the expected success of a stem cell intervention should include any preclinical evidence of safety and efficacy (ISCCR, 2016: recommendation 3.4). Furthermore, Sugarman (2016) and the ISSCR (2016) guidelines put forward that this should be complemented by a justification of why an innovative intervention is used instead of other existing alternatives. Behind this multiplicity of epistemic standards and proposed regulations, most defenders of innovation seem to agree that all reasonable agents should accept that innovative practice must be evaluated by informed judgments, based on detailed literature knowledge and reasonable peer agreement, about the merits of the interventions (London 2016, p. 30).

Finally, we wish to distinguish between futile and potentially inappropriate interventions. Following Bosslet et al., an intervention is futile in a narrow sense if it cannot accomplish the intended physiological goals, for example, administering antifungals as treatment for an acute myocardial infarction or cardiopulmonary resuscitation (CPR) on a patient with signs of irreversible death (rigor mortis, dependent lividity) (Bosslet et al. 2015, p. 1325). This narrow 
definition of futility precludes reasonable disagreement, but doctors should still care about patients and family perceptions if non-reasonable disagreement remains. This justifies the fact that, in general, responsible doctors should not administer futile interventions in this narrow sense for ethical reasons of non-maleficence, stewardship of social resources, and integrity (Bosslet et al 2015, p. 1327). However, there may be room for ethically permissible use of futile intervention in very limited situations, such as futile CPR for reasons of care towards the patient's family or other patients (Truog 2010, Choma et al. 2010). Hence, our use of futile interventions in a narrow sense is morally neutral, which is consistent with the neutrality of the definition of innovative practice (see Figure 1). In turn, an intervention is potentially inappropriate if it has at least some chance of accomplishing the effect sought, but competing ethical considerations may justify refusing to provide the intervention. For example, it is potentially inappropriate to initiate dialysis in a patient in a persistent vegetative state (Bosslet et al. 2015, p. 1324). Competing ethical considerations may be summarized in harm for patients or for others (Wilkinson, Petrou, and Savulescu 2018). As Bosslet et al. (2015) clarify, whether an intervention is potentially inappropriate is not only a technical judgment but a value judgment. Appropriate evidence and technical facts are necessary conditions for informed and reasonable judgment, but they have to be interpreted in relation to the patients' best interest, the patients' (or surrogates) values, and society's rules of fairness. Therefore, reasonable disagreement among the parties is possible and should be managed by a "fair process" of conflict resolution that could either favor the doctors' or the patients' (or surrogates') perspective.

If our exemplary cases are true cases of innovation, then their harm-benefit profiles show, in our definition, an insufficient level of evidence for their regular use in healthcare at or over a specific time period. However, even if the harm-benefit profile of an intervention shows 
insufficient level of evidence regarding safety and efficacy for regular use, such interventions may or not show sufficient level of evidence to be used as a "last chance" intervention. If responsible innovation is ethically permissible as the defenders argue, then new non-validated practice can still be a reasonable option in a limited number of cases if they have a sound scientific rationale and meet other appropriate conditions. The cases of Matthew Farrow or Molly Nash may meet such rationale. Refining the concept of innovation with explicit upper and lower bounds of evidence and introducing the category of potentially inappropriate practice allows us to deal with hard cases such as Jim Gass. In table 3, we suggest that, from a morally neutral point of view, the case of Jim Gass is neither a futile intervention nor validated practice. From a moral stance, Jim Gass seems as a paradigmatic case of potentially inappropriate practice because it did not comply with relevant ethical principles for use of innovative care (ISSCR 2016, Holzer and Mastroleo 2019a). Unfortunately, we cannot explore the details of the case at this point. However, interpreted as an exemplary case of innovation, the case of Jim Gass shows why a good definition of innovation should be morally neutral. We want to evaluate the ethical status of cases such as Jim Gass, but we first need a definition that captures what it is a case of, since different activities have different ethical principles, as we shall argue in the next section. In turn, our proposal also harmonizes with the literature that counts first or recent uses of unsuccessful interventions such as bed rest, bone marrow transplants for breast cancer, and diethylstilbestrol to prevent miscarriages, as exemplary cases of failed innovation (ACOG 2015, p. 3). Here, we depart from London (2006), who considers "improvement" a definitional attribute of "genuine" innovation. Our neutral definition captures all responsible or irresponsible and successful or failed cases of new non-validated interventions. 


\subsection{Intention to Benefit Individual Patients ("Practice")}

In the last part of our analysis, we state that if the use of new insufficiently-validated interventions is regarded as innovative practice, then the intention or main aim of such activity should be to benefit individual patients. This formulation is roughly equal to others in the literature such as the promotion of "patients' well-being" (National Commission 1979) or patients' best interests (Savulescu 2018). In traditional research ethics this means that innovation is practice, not research.

Here "intention" refers to a goal or aim to which an action is directed, that is, the intention with which someone acts (Setiya 2015). Intentional action neither presupposes success in achieving its aim, nor always is based on conscious reflective judgments at the time of acting (Scanlon 1998, p. 23). However, intention presupposes basic capacities of responsible agents, that is, agents that have the capacity of planning for the future and the capacity of giving reasons for actions according to adequate principles (Scanlon 1998, pp. 21-22).

The traditional research ethics' distinction between research and practice is based on two main aims, (P2) the promotion of "well-being of patients" and (R2) the contribution or development of “generalizable [scientific] knowledge” (National Commission 1979; Levine 1979). ${ }^{10}$ Hence, practice and research are defined as two different intentional activities. In turn, a different intention entails different principles for the ethical evaluation and different harm-benefit analysis of those activities (Weijer 2000; Bierley and Larcher 2009). ${ }^{11}$

\footnotetext{
${ }^{10}$ For our conceptual analysis, we will interpret "design" in the Belmont Report as the intention of an activity (Levine 2004).

${ }^{11}$ For completeness and economy of our conceptual analysis, it is useful to introduce self-interest as a third aim any act from a rational responsible agent may have (Taylor 2010). This allows us to formulate undue marketing or commercialization of new non-validated practice, a common concern in ethical frameworks, as inappropriate prioritization of self-interest over patient well-being and the commitment to contribute to generalizable scientific knowledge (e.g., ACOG
} 
We should note that aiming at both patients' well-being and generalizable scientific knowledge is possible in certain circumstances. The priority of one of these aims does not imply the exclusion of the other. For instance, in the case of Matthew Farrow, the same intervention promoted the well-being of an individual patient and contributed to the generation of generalizable scientific knowledge (Gluckman et al. 1989). However, hitting two birds with one stone is not always feasible or desirable. The development of generalizable scientific knowledge (research) requires systematization and planning. In turn, systematization and planning require time, special skills, and exclusive resources on top of whatever resources would be otherwise used for patients' care. Consequently, doing research may also carry an inherent potential for significant delay in promoting patients' well-being (Taylor 2010, p. 290). This explains why some authors defend that the duty to validate innovative practice should fall on research institutions rather than individual clinicians (Laurion \& Robertson 2019).

Even if we characterize innovation as a learning activity, it may also entail a potential loss in patients' clinical benefit (Faden et al. 2013, p. s21). For our purpose of defining innovative practice, is enough to show that in some cases different uses of interventions may entail prioritization and trade-offs between the well-being of patients and the development of scientific knowledge. Our aim in this paper is not to assess the ethical justification of this trade-offs (if any) or its regulation.

In turn, having the intention or main aim to benefit patients does not imply doing so in a responsible way. Responsible innovation is using new non-validated practice following certain

2015; ISSCR 2016, p. 25). However, to further simplify this analysis, here we will leave out problems of inappropriate selfinterest. 
principles. For instance, defenders of innovation consider that moving new non-validated practice into sound research should be an essential ethical requirement of responsible innovation (Laurion \& Robertson 2019) . This ethical requirement can be seen as a form of bridging the gap between practice (main aim to benefit patients) and research (main aim to contribute to generalizable knowledge). For the defenders, innovative practice must remain the exceptional case to avoid undermining public trust, exploiting patients' hope and delaying sound research (ISSCR 2016). This latter obligation is described in the literature as the "commitment to contribute to generalizable knowledge" (Sugarman 2012; ISSCR 2016) and is also present in the Belmont Report (National Commission 1979) and the Declaration of Helsinki (WMA 1964 [2013]: paragraph 37). However, as the literature shows, there are obstacles to operationalize this ethical requirement in real-world situations. For instance, lack of research infrastructures in new fields of medicine, lack of specific oversight structures for new non-validated practice, prohibition of national research funding in certain clinical areas (e.g. embryo research), etc. (ACOG 2015, pp. 4-5; Rosemann, Bortz, and Vasen 2019; Taylor 2010). Also, it remains unclear who should bear the duty of this ethical requirement (Laurion \& Robertson 2019).

Also, for the defenders of innovative practice, instrumental rationality sets further limits on the responsible use of new non-validated practice. This can be captured by the concept of opportunity or "right circumstances" (Taylor 2010). Right circumstances comprise the right timing (not too early... not too late) and proper measures, usually judged from the perspective of an expert (Stephenson 2005, p. 1). On the one hand, individual patients with unmet health needs and serious conditions have a limited period of time or "window of opportunity", if any, during which some intervention can be expected to promote their well-being. On the other hand, new knowledge and technology may entail potential uses that fit those unmet health needs, yet be still insufficiently 
validated for regular use. Opportunities for use of innovative practice lie in the fortunate intersection or right timing of both circumstances, "or not at all" (Larcher et al. 2018). The creative response of doctors, but also of informed patients or relatives, rests not only in realizing but also anticipating the existence of such opportunities. However, under the typical high levels of uncertainty, limited prospect of relief and the potential harms around these decisions, it is as much reasonable to accept human mortality and plan for a good end (Larcher et al. 2018).

Moreover, one important aspect of the attribute "intention" is its connection to the discussion on the justification and regulation of innovation with the adequate harm-benefit analysis. For the defenders, interventions considered as innovations in a traditional research ethics' sense should be subject to a harm-benefit profile evaluation according to the standards of medical practice. Medical practice is an activity in the best interest of the patient, and not according to the best interest of research (Levine 1979). For instance, if the new non-validated intervention is the only reasonable intervention for unmet health needs of serious conditions, the defenders argue that high risks can be reasonably accepted, even outside of sound research. However, if an intervention is potentially inappropriate, although its use could otherwise contribute to the benefits of future patients or generalizable scientific knowledge, the defenders may argue that responsible doctors should discourage or refuse it. If our conceptual analysis is sound, this shows that novelty or insufficient validation of an intervention for regular healthcare use are not enough to determine whether something is a new non-validated practice. It is the main aim of an intervention -to benefit an individual patient or to develop scientific knowledge- which entails different thresholds of harm-benefit analysis and ethical evaluation, as shown in traditional research ethics and the authors that are based on its intellectual work (e.g., Weijer 2000; Brierley and Larcher 2009; ISSCR 2016). 
Finally, to show the importance of the attribute of intention in our definition of new nonvalidated practice, we close this section with three exemplary types of new non-validated practice. Current regulations allow for these medical practices because their intention is to benefit individual patients with no other reasonable options. Hence, these activities are exempt from clinical research regulations as such. These cases show that neither levels of risk nor of lack of validation are necessary conditions for an intervention to be regarded as research-some arguing it ought to be different (Emanuel 2013).

First, it is the use of an intervention under expanded access (sometimes called "compassionate use"), that is, an exceptional use of an intervention outside of sound research aimed to promote patients' well-being for those who do not satisfy eligibility criteria and lack reasonable alternatives (Levine 2008, p. 217). For example, expanded access during phase 3 clinical trial of imatinib allowed some ineligible patients to access the drug given their urgent medical needs and lack of alternatives. It might be the case that expanded access was riskier than well-designed research. Still, as currently practiced, expanded access can be considered as type of new nonvalidated practice, and not research (e.g. FDA 2018b).

Second, some cases of post-trial access to investigational beneficial interventions, such as multiple antiretrovirals for HIV/AIDS in the late 1990s (Emery and Cooper 1997) or again imatinib in the early 2000s (Kolata 2005), serve as examples of the use of new insufficiently validated interventions for the benefit of individual patients with no reasonable alternative. Posttrial access differs from expanded access in the sense that it is restricted only to former participants of a research study (MRCT 2017, p. 77; Unguru et al. 2013, p. 4). Post-trial access to 
new non-validated practice may be riskier for different groups of participants. ${ }^{12}$ However, not every case of post-trial access would be a case of new non-validated practice. Post-trial access to new non-validated interventions should be called 'non-validated' only until an intervention becomes new validated, that is, when it reaches the level of safety and efficacy for regular healthcare use (MRCT 2017, fig. 1). Likewise, most of the research regulations in countries where they are available consider that post-trial access to a beneficial intervention is an exceptional medical activity with the aim to benefit former participants, not research (MRCT 2017, p. 74-5).

Third, novel "off-label" uses, that is, first or recent unapproved uses of an approved product by a regulatory authority, are also cases of innovation as new non-validated practice, until these uses show a sufficient level of validation for regular healthcare. An example is the successful use of ustekinumab, a biological product approved for psoriasis, in a 19-year-old patient with an immunodeficiency (leukocyte adhesion deficiency type 1 or LAD1) who previously showed a high risk of losing all his teeth and an intractable nonhealing wound in his lower back (Moutsopoulos et al. 2017; Sugarman 2017). Research regulatory authorities recognize the intention of the activity as different from research. Regulatory authorities use formulations such as "when the intent is the practice of medicine" or "in the best patient interest" to justify such uses in contexts where there are no reasonable alternative options (FDA 2018a).

The above stated examples illustrate that the intention to benefit an individual participant is a necessary attribute of the definition of innovation in traditional research ethics and our refined definition. To give those examples, we have presented the defenders' view that at least some cases

\footnotetext{
${ }^{12}$ Given that an intervention has been shown beneficial for the active arm of a study, it does not necessary follows that the very same intervention as post-trial access would be beneficial to the patients of the control group with a more advanced stage of disease (see the neuroblastoma case in Unguru et al. 2013).
} 
of expanded access, post-trial access and novel "off-label" uses are ethically permissible and responsible if they comply with certain ethical principles and institutional policies. However, both detractors and defenders of innovation may find our proposal useful. It shows our definition of innovation as new non-validated practice can unify, under one single concept, activities that might have been considered unconnected. Hence, we believe that our refined definition of innovation is important to further discuss the justification and regulation of these and other activities that can potentially be identified as new non-validated practice.

\section{CONCLUSION}

In this paper, we proposed an enhanced definition of innovation as new non-validated practice. We argued that this is a better term for referring to the first or recent use of interventions with an insufficient level of evidence of safety or efficacy for regular healthcare, and with the main aim to benefit individual patients. The objective of the paper has been to develop this definition as well as to gain rational acceptance for our proposal. We acknowledge that to forge consensus on new language use in medicine may take time. In the meantime, authors, research authorities, and other stakeholders should explain precisely what they mean when using the term innovation and the like (Lilford 2018). Our urge to propose a better definition of innovative practice for medicine is owed to the real-world consequences it has on patients, science, and public health. Just as the members of the National Commission did, we care about the appropriate use of language because it is necessary for the evaluation of responsible action, the prevention of confusion and the maintenance and promotion of public health (Confucius 2003, analect 13.3; Levine 1979, p. 25). 


\section{REFERENCES}

Agich, George J. 2001. Ethics and Innovation in Medicine. Journal of Medical Ethics 27 (5): 295-96. https://doi.org/10.1136/jme.27.5.295.

American College of Obstetricians and Gynecologists (ACOG). 2006, reaffirmed 2015. ACOG Committee Opinion No. 352: Innovative Practice: Ethical Guidelines. Obstetrics and Gynecology, 108(6), 1589-1595.

Ballen, Karen K., Eliane Gluckman, and Hal E. Broxmeyer. 2013. Umbilical Cord Blood Transplantation: The First 25 Years and Beyond. Blood 122 (4): 491-98. https://doi.org/10.1182/blood-2013-02-453175.

Baregheh, Anahita, Jennifer Rowley, and Sally Sambrook. 2009. Towards a Multidisciplinary Definition of Innovation. Management Decision 47 (8): 1323-1339.

BBC Staff. 2001. “Children's 'lifeblood' Hope.” BBC, October 10, 2001, sec. Health. http://news.bbc.co.uk/2/hi/health/1591933.stm, accessed August 132018.

Beauchamp, Tom L., and Yashar Saghai. 2012. The Historical Foundations of the Research-Practice Distinction in Bioethics. Theoretical Medicine and Bioethics 33 (1): 45-56. https://doi.org/10.1007/s11017-011-9207-8.

Bosslet, Gabriel T., Thaddeus M. Pope, Gordon D. Rubenfeld, Bernard Lo, Robert D. Truog, Cynda H. Rushton, J. Randall Curtis, et al. 2015. An Official ATS/AACN/ACCP/ESICM/SCCM Policy Statement: Responding to Requests for Potentially Inappropriate Treatments in Intensive Care Units. American Journal of Respiratory and Critical Care Medicine 191 (11): 1318-30. https://doi.org/10.1164/rccm.201505-0924ST.

Bothwell, Laura E., Jeremy A. Greene, Scott H. Podolsky, and David S. Jones. 2016. Assessing the Gold Standard - Lessons from the History of RCTs. New England Journal of Medicine 374 (22): 2175-81. https://doi.org/10.1056/NEJMms1604593.

Brierley, Joe, and Vic Larcher. 2009. Compassionate and Innovative Treatments in Children: A Proposal for an Ethical Framework. Archives of Disease in Childhood 94 (9): 651-54. https://doi.org/10.1136/adc.2008.155317.

Carroli, Guillermo, and Luciano Mignini. 2009. Episiotomy for Vaginal Birth. The Cochrane Database of Systematic Reviews, no. 1 (January): CD000081. https://doi.org/10.1002/14651858.CD000081.pub2.

Cartwright, Nancy. 2007. Are RCTs the Gold Standard? Biosocieties 1: 11-20. 
Chary, Krishnan V. 2016. Expedited Drug Review Process: Fast, but Flawed. Journal of Pharmacology \& Pharmacotherapeutics 7 (2): 57-61. https://doi.org/10.4103/0976500X.184768.

Choma, David, Kerri Cavanaugh, and Jamie Dwyer. 2010. "Is It Always Wrong to Perform Futile CPR? [Replies to Truog]." New England Journal of Medicine 362 (21): 2034-37. https://doi.org/10.1056/NEJMc1002983.

Cockburn, Tina, and Michael Fay. 'Consent to Innovative Treatment'. Law, Innovation and Technology 11, no. 1 (2 January 2019): 34-54. https://doi.org/10.1080/17579961.2019.1572996.

Confucius. 2003. Analects: With Selections from Traditional Commentaries. Translated by Edward Slingerland. Hackett Classics Series edition. Indianapolis, IN: Hackett Publishing Company, Inc.

Diaz, M., and D. Neuhauser. 2005. "Pasteur and Parachutes: When Statistical Process Control Is Better than a Randomized Controlled Trial.” BMJ Quality \& Safety 14 (2): 140-43. https://doi.org/10.1136/qshc.2005.013763.

Dresser, Rebecca. 2016. Terminally Ill Patients and the 'Right to Try' Experimental Drugs. In Silent Partners: Human Subjects and Research Ethics. Oxford, New York: Oxford University Press.

Druker, Brian J. 2009. Perspectives on the Development of Imatinib and the Future of Cancer Research. Nature Medicine 15 (10): 1149-52. https://doi.org/10.1038/nm1009-1149.

Earl, Jacob C. 2019. “Innovative Practice, Clinical Research, and the Ethical Advancement of Medicine." American Journal of Bioethics. Forthcoming.

Emanuel, Ezekiel J. 2013. Reconsidering the Declaration of Helsinki. Supplementary Appendix. The Lancet 381 (9877): 1532-1533.

http://www.thelancet.com/cms/attachment/2009236128/2031989121/mmc1.pdf, accessed March 32018.

Emery, Sean, and David A. Cooper. 1997. Drug Companies Have a Duty to Continue Treatment. BMJ: British Medical Journal 314 (7084): 889-889.

Faden, Ruth R., Nancy E. Kass, Steven N. Goodman, Peter Pronovost, Sean Tunis, and Tom L. Beauchamp. 2013. An Ethics Framework for a Learning Health Care System: A Departure from Traditional Research Ethics and Clinical Ethics. Hastings Center Report 43 (s1): S16-S27.

Faison, Amanda. 2005. The Miracle of Molly. 5280 Magazine, 2005. http://www.5280.com/2005/08/the-miracle-of-molly/. accessed March 82018 
Fins, Joseph J. 2017. “In Reply: Commentary: Deep Brain Stimulation as Clinical Innovation: An Ethical and Organizational Framework to Sustain Deliberations About Psychiatric Deep Brain Stimulation." Neurosurgery 80 (6): E271-72. https://doi.org/10.1093/neuros/nyx039.

Food and Drug Administration (FDA). 2018a. “Off-Label” and Investigational Use Of Marketed Drugs, Biologics, and Medical Devices - Information Sheet. WebContent. https://www.fda.gov/RegulatoryInformation/Guidances/ucm126486.htm, accessed August 13 2018.

Food and Drug Administration (FDA). 2018b. Expanded Access. WebContent. https://www.fda.gov/NewsEvents/PublicHealthFocus/ExpandedAccessCompassionateUse/def ault.htm, accessed December 4, 2018.

Gluckman, Eliane, Hal E. Broxmeyer, Arleen D. Auerbach, Henry S. Friedman, Gordon W. Douglas, Agnès Devergie, Hélène Esperou, et al. 1989. Hematopoietic Reconstitution in a Patient with Fanconi's Anemia by Means of Umbilical-Cord Blood from an HLA-Identical Sibling. New England Journal of Medicine 321 (17): 1174-78. https://doi.org/10.1056/NEJM198910263211707.

Gluckman, Eliane, Vanderson Rocha, Agnès Boyer-Chammard, Franco Locatelli, William Arcese, Ricardo Pasquini, Juan Ortega, et al. 1997. Outcome of Cord-Blood Transplantation from Related and Unrelated Donors. New England Journal of Medicine 337 (6): 373-81. https://doi.org/10.1056/NEJM199708073370602.

Holzer, F., \& Mastroleo, I. (2019a). Innovative Care in Latin America: Definition, Justification and Ethical Principles. In E. Rivera-López \& M. Hevia (Eds.), Controversies in Latin American Bioethics (pp. 145-176). https://doi.org/10.1007/978-3-030-17963-2 9

Holzer, F., \& Mastroleo, I. (2019b). Innovative Practice in Latin America: Medical Tourism and the Crowding Out of Research. The American Journal of Bioethics, 19(6), 42-44. https://doi.org/10.1080/15265161.2019.1602189

International Society for Stem Cell Research (ISSCR). 2016. Guidelines for Stem Cell Research and Clinical Translation. http://www.isscr.org/docs/default-source/guidelines/isscr-guidelinesfor-stem-cell-research-and-clinical-translation.pdf?sfvrsn=2, accessed March 92018.

Joffe, S. (2014). Evaluating Novel Therapies During the Ebola Epidemic. JAMA, 312(13), 12991300. https://doi.org/10.1001/jama.2014.12867

Joffe, Steven, and Holly Fernandez Lynch. 2018. Federal Right-to-Try Legislation - Threatening the FDA's Public Health Mission. New England Journal of Medicine 378 (8): 695-97. https://doi.org/10.1056/NEJMp1714054. 
Kahn, Jeffrey P., and Anna C. Mastroianni. 2004. Creating a Stem Cell Donor: A Case Study in Reproductive Genetics. Kennedy Institute of Ethics Journal 14 (1): 81-96.

Kass, Nancy E., Ruth R. Faden, Steven N. Goodman, Peter Pronovost, Sean Tunis, And Tom L. Beauchamp. 2013. The Research-Treatment Distinction: A Problematic Approach for Determining Which Activities Should Have Ethical Oversight. Hastings Center Report 43 (s1): S4-S15.

King, Nancy. 2002. The Line Between Clinical Innovation and Human Experimentation. Seton Hall Law Review 32 (3): 573-82.

Kolata, Gina. 2005. "Slowly, Cancer Genes Tender Their Secrets.” The New York Times, December 27, 2005, sec. Health. https://www.nytimes.com/2005/12/27/health/slowly-cancer-genestender-their-secrets.html, accessed August 132018.

Kolata, Gina. 2016. A Cautionary Tale of 'Stem Cell Tourism.' The New York Times, June 22, 2016. http://www.nytimes.com/2016/06/23/health/a-cautionary-tale-of-stem-cell-tourism.html, accessed March 32018.

Larcher, Vic, Helen Turnham, y Joe Brierley. 2018. "Medical Innovation in a Children's Hospital: 'Diseases Desperate Grown, by Desperate Appliance Are Relieved, or Not at All'". Bioethics 32 (1): 36-42. https://doi.org/10.1111/bioe.12381.

Laurion, Victor, y Christopher Robertson. 2019. "Why the Duty to Research Falls on Institutions Rather Than Individuals". The American Journal of Bioethics 19 (6): 44-46. https://doi.org/10.1080/15265161.2019.1607919.

Levine, Robert J. 1979. Clarifying the Concepts of Research Ethics. Hastings Center Report 9 (3): 21-26. https://doi.org/10.2307/3560793

Levine, Robert J. 2004. Robert Levine. Oral History of the Belmont Report and the National Commission for the Protection of Human Subjects of Biomedical and Behavioral Research Interview by Bernard A. Schwetz. https://www.hhs.gov/ohrp/education-andoutreach/luminaries-lecture-series/belmont-report-25th-anniversary-interviewrlevine/index.html.

Levine, Robert J. 2008. The Nature, Scope, and Justification of Clinical Research. In The Oxford Textbook of Clinical Research Ethics, edited by Ezekiel J. Emanuel, Christine Grady, Robert A. Crouch, Reidar K. Lie, Franklin Miller, and David Wendler, 211-21. Oxford University Press.

Lilford, Richard. 2018. "Health Service and Delivery Research - a Subject of Multiple Meanings." NIHR CLAHRC West Midlands News Blog (blog). November 30, 2018. https://clahrcwmblog.wordpress.com/2018/11/30/hsdr-subject-of-multiple-meanings/. 
Lipworth, Wendy, Cameron Stewart, and Ian Kerridge. 2018. "The Need for Beneficence and Prudence in Clinical Innovation with Autologous Stem Cells." Perspectives in Biology and Medicine 61 (1): 90-105. https://doi.org/10.1353/pbm.2018.0029.

Little, Margaret Olivia, and Marisha N. Wickremsinhe. 2017. Research with Pregnant Women: A Call to Action. Reproductive Health 14 (3):156. https://doi.org/10.1186/s12978-017-0419-x.

London, Alex John. 2006. Cutting Surgical Practice at the Joints: Individuating and Assessing Surgical Procedures. In Ethical Guidelines for Innovative Surgery, edited by Angelique M. Rietsma and Jonathan D. Moreno, 19-52. Hagerstown, MD: University Publishing Group.

London, A. J. (2018). Social value, clinical equipoise, and research in a public health emergency. Bioethics. https://doi.org/10.1111/bioe.12467

Lotz, Mianna. 2013. "Surgical Innovation as Sui Generis Surgical Research". Theoretical Medicine and Bioethics 34 (6): 447-59. https://doi.org/10.1007/s11017-013-9272-2.

Mastroianni, Anna. 2006. Liability, Regulation and Policy in Surgical Innovation: The Cutting Edge of Research and Therapy. Health Matrix: The Journal of Law-Medicine 16 (2): 351.

Miola, José. 2015. “Bye-Bye Bolitho? The Curious Case of the Medical Innovation Bill.” Medical Law International 15 (2-3): 124-54. https://doi.org/10.1177/0968533215605667.

Miola, José. 'Postscript to the Medical Innovation Bill: Clearing up Loose Ends'. Law, Innovation and Technology 11, no. 1 (2 January 2019): 17-33.

https://doi.org/10.1080/17579961.2019.1572706.

Montgomery, Jonathan. 'The "Tragedy" of Charlie Gard: A Case Study for Regulation of Innovation?' Law, Innovation and Technology 11, no. 1 (2 January 2019): 155-74. https://doi.org/10.1080/17579961.2019.1573402.

Moutsopoulos, Niki M., Christa S. Zerbe, Teresa Wild, Nicolas Dutzan, Laurie Brenchley, Giovanni DiPasquale, Gulbu Uzel, et al. 2017. "Interleukin-12 and Interleukin-23 Blockade in Leukocyte Adhesion Deficiency Type 1." New England Journal of Medicine 376 (12): 1141-46. https://doi.org/10.1056/NEJMoa1612197.

National Commission for the Protection of Human Subjects of Biomedical and Behavioral Research (National Commission). 1979. The Belmont Report: Ethical Principles and Guidelines for the Protection of Human Subjects of Research. Washington DC, US Government Printing Office.

Organisation for Economic Co-operation and Development (OECD). 2002. Technological Innovations. Glossary of Statistical Terms. https://stats.oecd.org/glossary/detail.asp?ID=2688, accessed March 32018. 
Palosuo, T., Antoniadou, I., Gottrup, F., \& Phillips, P. (2011). Latex Medical Gloves: Time for a Reappraisal. International Archives of Allergy and Immunology, 156(3), 234-246. https://doi.org/10.1159/000323892

Perdeaux, Lizzie. 2013. The Rare Diseases Genomes Project and Genomics England: By the NHS, for the NHS. BHD Foundation (blog). October 25, 2013. https://www.bhdsyndrome.org/forum/bhd-research-blog/the-rare-diseases-genomesproject-and-genomics-england-by-the-nhs-for-the-nhs/ accessed March 32018.

Rehm, Heidi L., Jonathan S. Berg, Lisa D. Brooks, Carlos D. Bustamante, James P. Evans, Melissa J. Landrum, David H. Ledbetter, et al. 2015. ClinGen — The Clinical Genome Resource. New England Journal of Medicine 372 (23): 2235-42. https://doi.org/10.1056/NEJMsr1406261.

Rietsma, Angelique M., and Jonathan D. Moreno, eds. 2006. Ethical Guidelines for Innovative Surgery. Hagerstown, MD: University Publishing Group.

Rosemann, Achim, Gabriela Bortz, and Federico Vasen. 2019. "Regulatory Developments for Nonhematopoietic Stem Cell Therapeutics: Perspectives From the EU, the USA, Japan, China, India, Argentina, and Brazil." In A Roadmap to Non-Hematopoietic Stem Cell-Based Therapeutics, edited by Xiao-Dong Chen, 463-92. Academic Press. https://doi.org/10.1016/B978-0-12811920-4.00019-7.

Savulescu, Julian. 2017. Press Release 'Vale Charlie. Practical Ethics (blog). July 24, 2017. http://blog.practicalethics.ox.ac.uk/2017/07/press-release-vale-charlie-prof-juliansavulescu/, accessed November 112018.

Savulescu, Julian. 2018. “Appendix 2, Savulescu's View.” In Ethics, Conflict and Medical Treatment for Children: From Disagreement to Dissensus [Internet], by Dominic Wilkinson and Julian Savulescu. Elsevier. https://www.ncbi.nlm.nih.gov/books/NBK537986/.

Scanlon, Thomas. 1998. What We Owe to Each Other. Cambridge, Mass.: Harvard University Press.

Schumpeter, Joseph A. 1947. The Creative Response in Economic History. The Journal of Economic History 7 (2): 149-159.

Sethi, Nayha. 2019. Regulating for uncertainty: bridging blurred boundaries in medical innovation, research and treatment. Law, innovation and technology 11(1): 112-133.

Setiya, Kieran. 2015. Intention. In The Stanford Encyclopedia of Philosophy, edited by Edward N. Zalta, Summer 2015. Metaphysics Research Lab, Stanford University. https://plato.stanford.edu/archives/sum2015/entries/intention/, accessed November 11 2018. 
Stephenson, Hunter W. 2005. Forecasting Opportunity: Kairos, Production, and Writing. Lanham: University Press of America.

Schuklenk, U., \& Smalling, R. (2017). The Moral Case for Granting Catastrophically Ill Patients the Right to Access Unregistered Medical Interventions. The Journal of Law, Medicine \& Ethics, 45(3), 382-391. https://doi.org/10.1177/1073110517737539

Sugarman, Jeremy. 2012. Questions Concerning the Clinical Translation of Cell-Based Interventions under an Innovation Pathway. The Journal of Law, Medicine \& Ethics 40 (4): 94550. https://doi.org/10.1111/j.1748-720X.2012.00723.x.

Sugarman, Jeremy. 2017. "NIH VideoCast - Ethics Rounds: Offering Patients Innovative Therapy: When Is It a Good Idea?" 2017. https://videocast.nih.gov/summary.asp?Live=21779\&bhcp=1.

Sutherland, R., E. A. P. Croydon, and G. N. Rolinson. 1972. Amoxycillin: A New Semi-Synthetic Penicillin. British Medical Journal 3 (5817): 13-16.

Taylor, Patrick L. 2010. Overseeing Innovative Therapy without Mistaking It for Research: A Function-Based Model Based on Old Truths, New Capacities, and Lessons from Stem Cells. The Journal of Law, Medicine \&Ethics 38(2), 286-302.

Truog, Robert D. 2010. “Is It Always Wrong to Perform Futile CPR?” New England Journal of Medicine 362 (6): 477-79. https://doi.org/10.1056/NEJMp0908464.

Unguru, Yoram, Steven Joffe, Conrad V. Fernandez, and Alice L. Yu. 2013. Ethical Issues for Control-Arm Patients after Revelation of Benefits of Experimental Therapy: A Framework Modeled in Neuroblastoma. Journal of Clinical Oncology: Official Journal of the American Society of Clinical Oncology 31 (5): 641-46. https://doi.org/10.1200/IC0.2012.47.1227.

Weijer, Charles. 2000. The Ethical Analysis of Risk. The Journal of Law, Medicine \& Ethics 28 (4): 344-61. https://doi.org/10.1111/j.1748-720X.2000.tb00686.x.

Wilkinson, Dominic, and Julian Savulescu. 2017. "After Charlie Gard: Ethically Ensuring Access to Innovative Treatment." The Lancet 390 (10094): 540-42. https://doi.org/10.1016/S0140$\underline{6736(17) 32125-6 .}$

Wilkinson, Dominic, Stavros Petrou, and Julian Savulescu. 2018. Expensive Care? Resource-Based Thresholds for Potentially Inappropriate Treatment in Intensive Care. Monash Bioethics Review, January, 1-22. https://doi.org/10.1007/s40592-017-0075-5.

World Health Organization (WHO). 2018. "Consultation on Monitored Emergency Use of Unregistered and Investigational Interventions (MEURI) for Ebola Virus Disease." https://www.who.int/ebola/drc-2018/notes-for-the-record-meuri-ebola.pdf, accessed November 112018. 
World Medical Association (WMA). 1964, last amended 2013. Declaration of Helsinki: Ethical Principles for Medical Research Involving Human Subjects. https://www.wma.net/policiespost/wma-declaration-of-helsinki-ethical-principles-for-medical-research-involving-humansubjects/, accessed November 112018

\section{INSTITUTIONAL SUPPORT}

Work on this paper was supported by The National Research Council of Argentina (CONICET), the Brocher Foundation for Bioethics, BioThera Research Institute for Philosophy of Translational Medicine (Biothera Foundation Grant), Brocher Foundation, DAAD Argentina, and UBACyT 20020150100193BA (Principle of autonomy, popular sovereignty, and theory of democracy) from the University of Buenos Aires. The views expressed in this paper are personal and do not necessarily reflect the policies of the institutions mentioned above.

\section{ACKNOWLEDGMENTS}

We are extremely grateful to Ariella Binik, Timothy Daly, Florencia Luna, Roland Mertelsmann, Jose Miola, Achim Rosemann, Diana Salmun, Julian Savulescu, Georg Starke, Tobias Schönwitz, Federico Vasen and Romina Zuppone for their valuable comments and suggestions. 